advanced non-mammary cancer and in the presence of advanced hepatic disease or severe surgical stress. ${ }^{9}$ In lungcancer patients, too, the ratio of androgen to corticosteroid excretion is significantly lower than normal, ${ }^{10}$ especially in those with a poor prognosis. In breast-cancer patients a negative discriminant has been shown to correlate with a depressed immune response. ${ }^{11}$ However, the abnormal index is not entirely the result of the presence of widespread disease, for patients with a rapidly growing localized tumour are said to be more likely to have a low androgen excretion than those with generalized disease. ${ }^{12}$ Nor does the discriminant function change with regression of breast cancer after endocrine ablation. ${ }^{13}$

There is some evidence that the presence of a negative discriminant can also reflect a factor influencing the development of breast cancer. Bulbrook and Hayward ${ }^{14}$ found an abnormally high proportion of women with a negative discriminant among breast cancer patients, and these were the ones who tended to have a worse prognosis than usual. It seems possible that a low excretion of androgen metabolites might precede the clinical onset of breast cancer, and a prospective cohort study has been carried out on the island of Guernsey since 1961. Already a significantly higher proportion with breast cancer has appeared in women excreting low levels of androgen, ${ }^{15}$ while the presence of a high proportion with negative discriminant among the sisters of these patients suggests a genetic influence. ${ }^{16}$

The implication of the low androgen excretion in these cases is not clear, for both Lemon ${ }^{17}$ and MacMahon and Cole ${ }^{18}$ have postulated that it is a relatively low level of circulating oestriol between puberty and the age of 25 which is the critical discriminant of a woman's breast cancer risk. A correlation has been claimed to exist between the excretion levels of androgens and oestrogens in normal premenopausal women, ${ }^{19}$ but a more recent report ${ }^{7}$ did not confirm the relation. A basic problem is that accurate methods do not exist for measuring the secretion rates of ovarian and adrenal steroids. One attractive hypothesis is that the development of breast cancer is favoured by a tendency to anovulatory cycles with unopposed action of oestrogen, especially in the first few years of menstruation. Such an abnormality could be associated with both low oestriol secretion and low androgen secretion by the ovaries and the adrenal cortex. ${ }^{20}$

\footnotetext{
${ }^{1}$ Bulbrook, R. D., Greenwood, F. C., and Hayward, J. L., Lancet, 1960, 1, 1154.

2 Miller, H., et al., British Medical fournal, 1967, 1, 147.

3 Ahlquist, K. A., Jackson, A. W., and Stewart, J. G., British Medical fournal, 1968, 1, 217.

4 Thomas, B. S., et al., Clinical Biochemistry, 1968, 1, 311.

5 Hayward, J. L., and Bulbrook, R. D., in Prognostic Factors in Breast Cancer, ed. A.P. M. Forrest and P. B. Kunkler. Livingstone, Edinburgh, 1968, page 383 .

${ }^{6}$ Hayward, J. L., Guy's Hospital Breast Clinic, unpublished data.

7 Metcalf, M. G., Fournal of Endocrinology, 1974, 63, 263.

8 Saez, S., in Mammary Cancer and Neuroendocrine Therapy, 1974, ed. B. A. Stoll. Butterworth, London, page 101 .

9 Durant, J. A., and Miller, H., British Medical fournal, 1973, 4, 767.

10 Rao, L. G. S., and Hewit, M. L., Lancet, 1970, 2, 1063.

11 Mackay, W. D., et al., Lancet, 1971, 2, 1001.
}

12 Gleave, E. N., in The Human Adrenal Gland and its Relation to Breast Cancer, ed. K. Griffiths and E. H. D. Cameron. Tenovus, Cardiff, 1969, page 86.

${ }^{3}$ Fotherby, K., and James, F., in Endocrine Therapy in Malignant Disease, ed. B. A. Stoll. W. B. Saunders, London, 1972, page 25.

${ }^{14}$ Bulbrook, R. D., and Hayward, J. L., Acta; Unio Internationalis Contra Cancrum, 1962, 18, 893.

15 Bulbrook, R. D., and Hayward, J. L., Lancet, 1967, 1, 519.

16 Bulbrook, R. D., Fournal of the National Cancer Institute, 1972, 48, 1039.

17 Lemon, H. M., Cancer (Philadelphia), 1969, 23, 781.

18 McMahon, B., and Cole, P., Cancer (Philadelphia), 1969, 24, 1146.

19 Adlercreutz, H., Luukainen, T., and Svanborg, A., Annales Medicina Experimentalis et Biologiae Fenniae, 1967, 45, 277.

${ }^{20}$ Sherman, B. M., and Korenman, S. G., Cancer (Philadelphia), 1974, 33, 1306.

\section{Royal College of Radiologists}

Though radiology now pervades almost every branch of medicine, the teaching of it remains inadequate at both the practical and academic levels. Few recently qualified doctors can feel that they have had sufficient grounding in the subject, yet it is a branch of practice that will cause them special anxieties owing to its medicolegal implications. On all sides we are told that radiology is being abused-and the dearth of academic departments must contribute to that abuse if it exists. Though Britain has painfully struggled to acquire four professional chairs in the subject and one or two more are in the offing, not one of the London undergraduate teaching hospitals has done so. The Royal Postgraduate Medical School is the one beacon in the metropolis.

The transformation of the Faculty into the Royal College of Radiologists, announced last week, is to be welcomed as a sign that the practitioners of this neglected branch of medicine are looking confidently to the future. Confidence is all the more necessary in view of what Dr. J. W. D. Bull ${ }^{1}$ has called some "disquieting figures." These were derived from an unpublished memorandum of the Department of Health and Social Security, and they indicated that within a decade something approaching half of the present radiologists will have retired. Yet the doldrums in which this branch of medicine has traditionally been allowed to linger are in striking contrast to the brilliant technical advances that radiology has made, the most recent and remarkable of which is computer assisted tomography. ${ }^{2}$ In the opinion of many leading radiologists this is the greatest single achievement in technique since Roentgen's rays were first applied to medical purposes. And ironically enough its inventor, Mr. G. N. Hounsfield, who was elected F.R.S. for this work last month, is a citizen of the very country that has so signally neglected this branch of medicine - Great Britain. The royal college's first president, Professor Howard Middlemiss, of Bristol, and his colleagues deserve the good wishes of the whole profession in getting off to a flying start.

${ }^{1}$ Bull, J. W. D., British Medical fournal, 1974, 3, 394.

2 British Medical fournal, 1974, 2, 623. 